\title{
The political use of knowledge in the policy process
}

\author{
Falk Daviter ${ }^{1}$
}

Published online: 22 September 2015

(C) The Author(s) 2015. This article is published with open access at Springerlink.com

\begin{abstract}
The role of knowledge in the policy process remains a central theoretical puzzle in policy analysis and political science. This article argues that an important yet missing piece of this puzzle is the systematic exploration of the political use of policy knowledge. While much of the recent debate has focused on the question of how the substantive use of knowledge can improve the quality of policy choices, our understanding of the political use of knowledge and its effects in the policy process has remained deficient in key respects. A revised conceptualization of the political use of knowledge is introduced that emphasizes how conflicting knowledge can be used to contest given structures of policy authority. This allows the analysis to differentiate between knowledge creep and knowledge shifts as two distinct types of knowledge effects in the policy process. While knowledge creep is associated with incremental policy change within existing policy structures, knowledge shifts are linked to more fundamental policy change in situations when the structures of policy authority undergo some level of transformation. The article concludes by identifying characteristics of the administrative structure of policy systems or sectors that make knowledge shifts more or less likely.
\end{abstract}

Keywords Evidence-based policy making - Knowledge creep - Knowledge utilization · Organizational epistemology · Punctuated equilibrium theory

\section{Introduction}

The role of knowledge in the policy process has remained a central theoretical puzzle in policy analysis and political science. Yet studies of knowledge use have profited little from the parallel debates in both fields of research. As Sabatier and Jenkins-Smith (1988: 123)

Falk Daviter

daviter@uni-potsdam.de

1 Department of Economics and Social Sciences, University of Potsdam, August-Bebel-Str 89, 14482 Potsdam, Germany 
pointed out some time ago, 'one of the most surprising — and distressing — aspects of the literature on knowledge utilization is that it has developed largely independently of the literature in political science on the factors affecting the policy process.' Despite repeated calls for a better integration of both literatures in the years that followed (e.g., Jones et al. 2014: 166-67; James and Jorgensen 2009: 143; Radaelli 1995: 162; Rich and Oh 1993: 85; Webber 1992: 414), most of this research continued to develop independently. This has resulted in a fragmented empirical grasp and unreconciled theoretical understandings of the role of knowledge in the policy process. The more recent surge in the literature on evidence-based policy making has focused the debate on questions of how knowledge use can improve the quality of policy choices. These studies largely follow in the tradition of early knowledge utilization research (Newman and Head 2015: 384; Kay 2011: 236; Weiss et al. 2008: 44). While this literature has made significant progress (see Mead 2015; Newman and Head 2015 for a recent discussion), it has contributed little to advance our theoretical understanding of the role of knowledge in the policy process. Instead, most of this debate appears premised on a preconceived understanding of how knowledge should be used in the policy process, and to what end. This has steered the debate further away from a broader consideration of the different functions of policy knowledge. Understanding different types of knowledge use and how they affect the policy process therefore remains a key concern of current research.

This article argues that an important yet missing piece of this puzzle is the systematic exploration of the political use of policy knowledge. As the article will show, the political use of knowledge is given surprisingly short shrift in the standard literature. Instead, much of the debate remains firmly rooted in the assumption that 'politics' constrains the use and counteracts the effects of knowledge in policy making. The article challenges this notion by elaborating an alternative theoretical perspective. This perspective is premised on the view that knowledge is bound by the organizational structure of policy making and used in the policy process to expand policy authority and exercise control. A major theoretical implication of this perspective is that certain types of policy conflicts can become catalysts of knowledge use that affect the policy process in fundamental ways. The article therefore argues that the political use of knowledge can be linked to a much more diverse set of policy dynamics than covered by the standard literature. This literature identifies the slow, indirect and cumulative effect of 'knowledge creep' (Weiss 1980, 1982, 1986) as the preeminent influence of analytic information in the policy process. In contrast, this article argues that shifts in the political knowledge base can interact with structural determinants of policy change to produce fundamental policy readjustments that are more akin to policy punctuations. This type of knowledge shift is not caused by policy learning in given decision-making structures, but by political and administrative contestation over the way issues are categorized and problematized in the policy process.

The article is structured as follows. The next section provides a brief introduction to the theoretical debate. The discussion then focuses on existing concepts of the political use of knowledge in the policy process. This literature is found to be deficient, and a revised conceptualization of political knowledge use is proposed. The article then explores the organizational foundations of knowledge use and finally discusses how a focus on the organizational characteristics of policy system or sectors can help to explain different types of knowledge effects in the policy process. The conclusion summarizes the main points and highlights how the analysis contrasts with established positions in this field of research. 


\section{Knowledge creep and the enlightenment model of knowledge use}

Much of the early academic debate in this field was driven by an expanding understanding of policy knowledge and its functions in the policy process. Initially, the focus was limited to concrete or technical knowledge and its role in improving policy choices. This type of instrumental use of policy information has sometimes been called the 'engineering model' (Knorr 1977). Research in this tradition soon faced a major paradox. While an ever-increasing amount of policy-relevant information was produced and disseminated, studies of knowledge use almost equivocally attest to the fact that little of this knowledge ever enters the decision-making realm. In light of these disconcerting results, a competing interpretation of research findings emerged that challenged the conceptual premises of the debate. The perceived gap between knowledge production and utilization came to be seen partially as an artifact of the exceedingly narrow understanding of knowledge use that dominated much of the early studies in this field of research (Caplan 1979: 468; Pelz 1978). The distinction between concrete and conceptual knowledge use was introduced to underline that early research was struggling with this multifaceted role of knowledge in the policy process (Weiss 1977a; Rich 1977). This research emphasized that there are more ways in which knowledge can influence policy choices than by producing reliable empirical predictions about the relationship between preconceived means and ends. Weiss (1977b) claimed that knowledge can inform policy making also by challenging the underlying assumptions and analytical concepts that structure policy choices. Her enlightenment model highlights how information can enter the policy process in ways that alter the decision makers' fundamental understanding of the issues at stake. Policy knowledge, according to Weiss (1999: 146), supplies decision makers with the 'background of ideas, concepts and information that increased their understanding of the policy terrain.' From this perspective, the primary function of information in the policy process is seen as providing 'insights into the nature of social problems' (Weiss 1995: 141). As a result, researchers also began to operate with a much broader definition of policy knowledge. Weiss' (1986: 279) use of the term, for example, encompasses 'research, analysis, evaluation, data.' Most of the more recent contributions have similarly opted for such a broader definition of policy knowledge. Radaelli (1995: 162-63), in one of the classic articles on the issue, acknowledges the role of 'hard' policy information defined as scientific knowledge, but argues that this type only constitutes one end of a continuum. At the same time, the enlightenment model also established a new understanding of the process through which knowledge influences policy choices. While previous research on instrumental knowledge use was associated with expectations of direct and immediate effects of available information on policy choices, the enlightenment model describes policy dynamics that work 'in the long term' (Weiss et al. 2005: 14). 'Perhaps it takes 5 or 10 years or more before decision makers respond to the accumulation of consistent evidence,' Weiss (1993: 98) argues. One reason for this was that conceptual knowledge use was seen as much more diffuse and indirect. To capture the long-term effects of information on the policy process, Weiss (1980, 1982, 1986) introduced the term 'knowledge creep.' According to Weiss, new information and ideas 'seep into people's consciousness and alter the way that issues are framed and alternatives designed' (1999: 471). Knowledge creep therefore describes a 'slow trickle' that produces 'slow results' (Weiss 1999: 472).

Several decades after its initial formulation, the enlightenment model has established itself as one of the dominant research perspectives in studies of knowledge use. It has 
been assessed to capture 'the most important effect that research and evaluation have had on policy' (Weiss et al. 2005: 14). At the same time, the model remains insufficiently theorized in key respects. Weiss (1986: 278) herself notes that the concept of knowledge creep is a largely descriptive metaphor and that little is known about the mechanisms and conditions under which information produces enlightenment effects. While students of knowledge use have grown increasingly impatient with a field of study that is 'generally silent on the range of underlying mechanisms' (Mark and Henry 2004: 37), few successful attempts have been made to address these shortcomings (Weiss et al. 2005: 26-27). Arguably the most prominent theoretical elaboration of the enlightenment model in the context of policy research can be found in the work of Paul Sabatier on policy learning. Sabatier developed his well-known framework as an attempt to build directly on the enlightenment model and integrate it into theories of policy learning (Sabatier 1988: 158; 1987: 649; Sabatier and Jenkins-Smith 1988: 124). Yet in terms of its contribution to knowledge research, Sabatier's work stands out as conservative. In contrast to the enlightenment model, Sabatier's main interest lies with the role of technical knowledge in the policy process (e.g., Sabatier 1997: 4). Partially as a result of his more limited focus, he finds that knowledge interventions are most likely to affect policy choices if decision-making power is delegated to apolitical expert arenas, and when the issues under consideration allow for straightforward scientific appraisal (Sabatier 1997: 4, 1988: 159). Knowledge effects are seen as primarily affecting secondary aspects of policy formulation, such as instrument choice and implementation strategies. Changes at the level of the underlying perception of problem structures, on the other hand, are largely shielded from evidentiary influence. Unsurprisingly, critics have charged that his theory of policy learning departs substantially from key interests of the enlightenment model that was its original point of departure (e.g., James and Jorgensen 2009; Fischer 2003; Bennett and Howlett 1992).

With the outlined shift from instrumental to conceptual use, knowledge research has overcome a rationalist bias that characterized the early work in this field, but it has also remained limited in several respects. Founded on a largely implicit notion of policy learning, the use of conceptual knowledge has become closely associated with a single type of knowledge effect that is described as diffuse, indirect and difficult to observe. Even more importantly, research in the enlightenment tradition also remains solidly focused on the substantive dimension of knowledge use. It largely ignores the question of how the influx of knowledge about the nature and structure of policy problems affects the political process beyond informing the search for suitable policy solutions. The next section will argue that conceptual knowledge also has a political function in the policy process that much of the existing literature fails to address. As a result, central mechanisms of knowledge transfer and corresponding knowledge effects in the policy process have remained underexplored.

\section{Reconceptualizing the political use of policy knowledge}

The political or strategic use of conceptual knowledge is given surprisingly short shrift in the standard literature (see Whiteman 1985). While political use is frequently listed alongside instrumental and conceptual use as a major area of inquiry (e.g., Head 2013), existing research on the political use of knowledge has adopted a rather limited research focus. Most studies conceptualize the political use of knowledge as little more than a "fig 
leaf of rationality for policy positions adopted on altogether different grounds' (Weiss and Gruber 1984: 228). In a still influential contribution, Carol Weiss (1977a: 15) defines political use as the type of use that is meant 'to support a predetermined position.' Similarly, Whiteman (1985: 206), in an otherwise critical review of the literature, proposes a definition of political use as the 'use of analytic information to advocate and reaffirm policy positions after they have been determined.' According to his typological scheme, the fact that information enters the decision-making process only after policy positions have been reached is the 'only significant difference' (Whiteman 1985: 206) between political use and other types of knowledge use. The vast majority of research follows in this tradition. In a recent overview of the literature, Weible (2008: 620) discusses existing studies of political use in almost identical terms and defines political use as strategies to 'legitimize previously made policy decisions.' Owing in large part to the narrow conceptual focus, the political use of knowledge is often described as little more than symbolic posturing and has been associated with political behavior that uses analytical information 'selectively and often distortingly' (Knorr 1977: 171). Critics of this limited understanding of the phenomenon maintain that the political function of knowledge remains poorly understood and that by focusing on the use of evidence as a way to conceal predetermined preferences existing studies have addressed 'a rather uninteresting tip of the iceberg' (Weiss and Gruber 1984: 228). Yet the quest to explore more extensively how knowledge can gain political currency beyond the well-established analysis of substantive and symbolic use has proven difficult.

In an early attempt to expand the focus of this debate, Weiss and Gruber depart from the more general observation that 'in a world of complex governance and shared control, it is not enough to discover the best possible decision' (Weiss and Gruber 1984: 226). Instead, the authors argue, policy makers 'typically value knowledge for its contributions to the exercise of political control' (Weiss and Gruber 1984: 225). Their argument constitutes a fundamental break with standard perspectives in this field of research. While existing studies acknowledge the fact that some of the more fundamental policy conflicts are not about policy substance per se, but also about the distribution of policy authority and political control, these types of conflicts are almost invariably seen as diminishing both the likelihood of knowledge use and its impact on policy choices. The notion that conflict over the distribution of policy competences can be a catalyst of knowledge use and affect the policy process in fundamental ways has remained uncharted territory. As a result, important research questions have been largely omitted from the academic debate.

In the broader field of policy research, arguments that inquire into the link between knowledge use and the distribution of policy authority have played a more prominent role. Discussing Hall's (1993) seminal work on policy change, for example, Baumgartner (2013: 240) in a recent review reiterates Hall's (1993: 280) point that if conflicting knowledge triggers fundamental policy change, this will likely happen in conjunction with significant shifts in the distribution of policy authority. Whether or not competing knowledge affects policy choices, Baumgartner (2013: 253) goes on to argue, often depends on whether available knowledge can be used to challenge established patterns of influence in the policy process. On a more general level, Hall's work also begs the question of whether knowledge use that hinges on parallel shifts in policy authority can still be usefully categorized as a type of policy learning (Pierson 1993: 614-615). Instead, Hall's (1993) argument about fundamental or paradigmatic policy change draws attention to the fact that policy knowledge can be understood to inform the choices of a given set of actors or institutions who are empowered to set policy in a certain area, or it can be understood to inform the 
choices over how the authority to set policy is allocated in the first place. As Jones (1994: 50) points out, policy problems are 'not just illuminated by information, they are framed by it.' Every piece of information that enters the policy process highlights certain aspects about the scope and nature of a policy problem and ignores others. Competing expertise is therefore central to claims concerning the contours and classification of policy problems. This has direct implications for the way policy systems address problems and how they allocate authority over policy choices. Yet research on knowledge use provides no conceptual category to study these effects. For the most part, even more recent theoretical discussions of knowledge utilization conflate conceptual and enlightenment use (e.g., Newman and Head 2015: 388; Mark and Henry 2004: 36), and they overlook that conceptual knowledge can have both substantive and political effects on policy. It is therefore paramount that knowledge research expands its understanding of the political use of knowledge in the policy process. This argument follows Whiteman's (1985) two-dimensional perspective on knowledge use. The 'key to developing a two-dimensional perspective,' Whiteman (1985: 205) argues, 'is recognizing that strategic use is not distinct from concrete and conceptual use. Instead, like substantive use, strategic use can be either concrete or conceptual.' At the same time, this article differs from Whiteman (1985) on the level of the typological distinctions. Any definition of the political use of knowledge that points exclusively to the use of knowledge as post hoc rationalization of predetermined policy positions as the defining characteristic reduces the scope of analysis to such an extent as to prevent any meaningful investigation of the phenomenon.

\begin{tabular}{lll}
\hline & Dimensions of knowledge use & \\
\cline { 2 - 3 } & Substantive & Strategic \\
\hline Concrete & Instrumental & Symbolic \\
Conceptual & Enlightenment & Political \\
\hline
\end{tabular}

A more reflective conceptualization of the political use of knowledge would encompass the use of analytic information to establish or contest authority and control over policy choices. This conceptualization points to rather different conditions and mechanisms of knowledge use and different effects on the policy process than those described by the literature discussed above. For example, the enlightenment model theorizes that substantive use of conceptual knowledge is most likely to play a role in the policy process if it 'disturbs few social arrangements and institutional interests' (Weiss 1976: 225). The reverse logic applies in the case of the political use of conceptual knowledge. Here knowledge enters the decision-making process because policy authority is contested and competing organizations draw on knowledge to shape problem perceptions and substantiate claims of competence in their attempts to gain issue control. This view highlights that the organizational level of analysis is central to arguments of political knowledge use. While organizational structures limit knowledge use and transfer in important ways, they also affect the way in which conflicting knowledge enters the policy process. The next section will address the role of the organizational level of analysis in explanations of knowledge use in more detail. At the same time, the effects of political knowledge use on the policy process are expected to differ substantially from the effects of knowledge use in the enlightenment model. The notion of knowledge creep assumes that information slowly 
alters the way decision makers address substantial policy problems as knowledge accumulates and diffuses over time. The political use of knowledge highlights the transformative effects of competing knowledge when policy authority and the delineation of responsibilities become contested. This part of the argument will be addressed in the section after next.

\section{Organizational epistemologies and the limits of learning}

As discussed above, the vast majority of the more recent research on knowledge use is premised on the notion that knowledge is most relevant when it contributes conceptual insights into the nature and structure of policy problems. Studies of conceptual knowledge use therefore inquire how policy knowledge affects the way policy issues are framed for decision making (Weiss 1999: 471; Radaelli 1995: 164). Both the prevailing analytical understanding of the policy problem and the possibilities for competing information to affect the way issues are framed in the policy process are influenced by the organizational setting. Schön and Rein (1994: 31), for example, discuss the fact that policy frames do not exist in an institutional vacuum, and their research shows that frames are often embedded in administrative decision-making structures (e.g., Rein and Schön 1996: 95; Schön and Rein 1994: 28). But an early emphasis in this line of research on the level of secondary institutional organization as a 'decision matrix' (Rein and White 1977: 265) that structures policy development was not rigorously explored. The fact that much of this literature ignores the structural level of analysis has repeatedly drawn criticism (e.g., Feldman 1989: 145ff.; Huberman 1987: 589). The need to gain a more systematic understanding of how the organizational characteristics of policy-making systems influence the processing of information has therefore been highlighted repeatedly (e.g., Rich and Oh 2000; Oh 1997a, b; Rich 1991).

Theoretical attention to the role of the organizational channels of information processing becomes even more relevant if one recognizes that policy choices are commonly made in highly information-rich environments (Simon 1973a: 270; Knott and Wildavsky 1980; Wildavsky 1983: 29; Weiss 1995: 149; Weiss 1999: 478; James and Jorgensen 2009: 148). While earlier studies of knowledge use frequently treated the supply and dissemination of information as problematic, more recent studies have argued that policy making takes place in an environment routinely saturated with information. Under conditions of information overload, theoretical interest shifts from the production and dissemination to the 'filtering' and 'mobilization' of policy knowledge (James and Jorgensen 2009: 156). In the policy process, this is largely accomplished through organizational structures and hierarchies (Jones 2001). At the most basic level, every department or policy unit can be analyzed as the organizational expression of a partial representation of complex policy problems. Jurisdictional boundaries and departmental specialization delineate the relevant knowledge bases, guide information search and preselect evaluative criteria used in the analysis of available expertise. In short, organizations exist to suppress information (Wildavsky 1983: 29).

Interest in knowledge use as organizational behavior leads Dery $(1983,1986,1990)$ to propose that studies of the policy process should focus more squarely on the role of organizational epistemologies. Following Holzner and Fischer (1979), he stresses that a core organizational function in the policy process is to provide perceptual filters and direct attention toward selective aspects of the task environment (Dery 1990: 31, 1986: 
20). How political and administrative actors search for policy information and how they interpret them depend foremost on the organizational context. Policy knowledge, Dery (1990: 132) therefore argues, is the 'product of political and bureaucratic processing.' Since bureaucratic and political organizations acquire, interpreted and evaluated information based on preexisting 'conventions of knowing' (Dery 1986: 19), information that conflicts with the organizational premises is typically suppressed or rejected (Dery 1990: 128). An important consequence of the selective organizational processing of policy knowledge is that issue perceptions and problem definitions are much more likely to vary across different organizational units or subunits of government at any given point in time than within a given organizational unit over time. The focus on organizations as epistemologically closed systems thus contrasts sharply with the naïve empiricism of theories that uncritically extend notions like experimentation, verifiability or fallibility to knowledge use by political and administrative agencies and highlights the limits of organizational learning from experience as a major driver of conceptual knowledge use in the policy process. Instead, it understands knowledge use as bound by organizational rules of observation and inference, 'such rules guide inquiry but cannot be challenged by it' (Dery 1990: 25; see also Holzner and Fisher 1979: 231). As a result, Dery rejects the Kuhnian notion of learning from anomalies that informs major strands of the literature on policy learning, such as Hall's (1993) concept of paradigmatic policy change or Sabatier's (1986: 667, 1988: 145) understanding of changes in the policy core of advocacy coalitions, as a plausible explanation of organization behavior. Instead, Dery (1990: 32) contends that the potential for conflicting knowledge to enter the decision-making process 'lies not in experimentation and verification but in contest.'

While political and administrative organizations are understood as epistemologically closed systems, they rarely acquire the position of uncontested arbiters of policy knowledge. Organizational epistemologies built into the policy process work to suppress the transfer and use of information in their respective decision domains. But the resulting partial representations of complex policy problems also offer political incentives for the use of conflicting information. Policy research increasingly emphasizes that many of the most relevant policy problems are 'complex' (Simon 1962), 'ill-structured' (Simon 1973b), or 'wicked' (Rittel and Webber 1973). Ill-structured or complex policy problems by definition defy easy categorization. They frequently require policy responses that depend on highly integrated government programs or remain partial at best (Head and Alford 2015; Weber and Khademian 2008). Conflict over policy authority and contestation of jurisdictional boundaries are therefore not only common features of this type of policy making, but also difficult to resolve. While conflicts over the structure of policy problems cannot be settled by analysis (Lindblom 1968: 14), competing policy knowledge often gets drawn into the policy process in their wake. The 'potential interference of contestants, or contesting frames of reference,' Dery (1986: 21) argues, undercuts the ability of government organizations to ignore competing problem perspectives and conflicting information. Conflicting knowledge thus becomes more critical in the policy process when organizational frames of reference are contestable. The following section discusses the theoretical and empirical implications of this perspective in the context of the literature on policy change. The last section then summarizes the main points and discusses them in the context of the larger academic debates in this field of research. 


\section{Two types of knowledge effects in the policy process: knowledge creep and knowledge shifts}

This article started out from the observation that research on knowledge use and studies of the policy process have largely developed independently from one another. One important consequence of the parallel development of these literatures is the limited way in which knowledge use has been linked theoretically to different types of policy change. The established view is that consolidated evidence has a cumulative effect on the way policy makers make sense of the problems they face and transforms policy choices incrementally over time. This dynamic has become known as knowledge creep. Its formulation was informed by a revised understanding of the way knowledge influences policy choices that emphasizes conceptual rather than instrumental knowledge use. While the above analysis followed previous debates in terms of its focus on conceptual knowledge use, it also remained dissatisfied with the limited theoretical exploration of the political function of conceptual knowledge. The reconceptualization of the political use of knowledge developed in the previous sections sheds new light on the role of knowledge in the policy process. The baseline assumption is that policy knowledge can be used to contest given structures of policy authority and that knowledge used to reframe a policy along the lines of contestable boundaries of policy authority will enter the policy process more forcefully than other types of knowledge. Understanding organizations as epistemologically closed systems underscores that under conditions of low contestability even mounting pressure for adaptation will likely be met by attempts to disregard and dismiss, if not outright discredit, conflicting knowledge. The notion of contestability therefore implies that the scope and likelihood of knowledge effects depend foremost on the degree to which conflicting knowledge can be used by potential contestants to construct knowledge claims that challenge established patterns of influence. Dery (1990: 128) therefore concludes that administrative and political competition and dispersed policy responsibilities are the main features of policy systems that 'constrain the tendency to suppress, and the inclination to overlook disconfirming data' in the policy process.

In her later research, Carol Weiss (1999: 480) appears to adopt a similar point of view when she argues that knowledge stands a better chance at affecting policy change in 'competitive political systems' and under conditions of 'decentralization' of policy that leave government control dispersed across different levels. The existence of 'multiple points of access within the policy system,' Weiss (1999: 480) holds, is a central factor in explanations of knowledge use in the policy process. While her empirical observations of the conditions of knowledge use thus largely correspond with the preceding analysis, it remains unclear whether policy systems with high levels of fragmentation and competition are expected to facilitate the diffuse and incremental processes of knowledge creep that are the focus of her research or other types of knowledge effects. In major strands of policy research, the view that fragmentation and contestability of policy authority are linked to discontinuous and disproportional knowledge use rather than incremental knowledge creep is more widely established. These literatures build on the analysis of administrative structures as mechanisms of compartmentalization in political decision making. Complex problems are factorized into more manageable tasks that are addressed separately in largely independent subsystems (Simon 1973a: 270). While the autonomous processing of different aspects of policy in independent subsystems is a rational response to the complex and information-rich task environments of modern policy-making systems, the 'design for informational autonomy' (Huber 1991: 104) also reduced the possibility for knowledge 
transfer and organizational learning. At the same time, fragmented responsibilities and overlapping competences generate an influx of incompatible information and create pressure on existing decision-making structures to accommodate competing knowledge claims (Workman et al. 2009: 84). Because partial problem perceptions and selective organizational attention are structurally embedded, the transfer and use of conflicting knowledge and the resulting policy adaptation are typically seen as episodic and delayed rather than incremental and continuous. Irregular punctuations of the policy process are therefore the expected result (Jones and Baumgartner 2005).

Conceptual knowledge that affects policy choices in this way is more accurately described as knowledge shift rather than knowledge creep. Conflicting information enters the policy process when policy authority is reassigned to new institutional structures of decision making. In such cases, the former informational foundation of policy making is replaced by a new knowledge base and the existing policy regime is replaced. Conflicting knowledge is therefore not integrated into existing policy structures, but plays a major part in replacing them. This line of argument places the political use of conceptual knowledge more firmly in the context of theories of policy punctuation and greatly expands the range of policy dynamics with which the use of conceptual knowledge in the policy process is theoretically associated. It also conforms with the widely accepted notion that fundamental policy change is most likely when policy institutions themselves undergo transformation, while incremental policy change as described by the literature on knowledge creep is characteristic of decisions reached within existing policy structures (Howlett and Migone 2011: 57-58). While all policy systems adjust the ways in which they assign policy authority from time to time (Baumgartner and Jones 1993), some policy systems or sectors are expected to be more responsive to competing knowledge and more easily adjusted structurally. This in turn has effects on the scope and likelihood of knowledge effects on policy change. The central question thus becomes under what conditions knowledge creep or knowledge shifts are the more likely effects of conflicting information in the policy process.

Both types of knowledge effects appear more likely that the more open and dispersed policy authority is organized in a given policy system. This is viewed as a precondition for conflicting knowledge to even enter the policy process. The preceding analysis therefore implies that the question of whether knowledge creep or knowledge shifts prevail depends largely on the way the organization of policy authority renders organizational knowledge more or less contestable. Contestability is influenced primarily by features of the policy system at the level of secondary institutional organization, or what Rein and White (1977: 265) have called the 'decision matrix.' This places the analytical emphasis on the organizational characteristics of administrative structures, such as the degree and nature of administrative specialization, the rigidity of departmental boundaries, and the degree of overlap and duplication of responsibilities across policy organizations. The degrees of vertical specialization, for example, offer insights into the extent to which administrative units are placed hierarchically under direct political control or remain organizationally independent from political influence. In the case of strong vertical specialization, organizational epistemologies can be expected to be generally more distinct and pronounced, oftentimes in form of allegiance to some form of scientific or professional expertise. Independent central banks, for example, are generally expected to pay special attention to some select indicators, such as the level of inflation, in assessing conflicting information concerning overall economic performance. Their organizational epistemologies and organizational insulation from political influence thus render them generally less susceptible to knowledge shifts. Knowledge creep appears the more likely effect of conceptual 
knowledge use. If we turn the attention to the dimension of horizontal specialization, contestability will depend largely on the respective logic of departmental organization. If policy authority in a public health sector is organized in a way that separates responsibilities according to a functional criterion between one branch of the organization that deals with treatment and another that deals with prevention, for example, research that points toward prevention as the more effective policy approach would likely cause extensive political knowledge use and open up the possibility for far-reaching knowledge shifts. If policy authority was organized by sector, on the other hand, this type of knowledge effect would appear far less likely. Knowledge creep may still occur, but almost certainly with less far-reaching results and only after long-term consolidation and convergence of available evidence. Since political knowledge use is more likely to play a role at the intersection of competing organizational frames of reference, duplication and overlap of policy responsibilities generally make knowledge shifts more likely. Knowledge that links the risk of homelessness to mental illness, for example, can affect shifts of policy authority from social programs aimed at financial assistance to public health programs. If policy responsibilities in this sector are organized in a single more unitary and vertically integrated administration, on the other hand, this would shield the organizational knowledge base more effectively from the risk of intrusion. Conflicting information is likely to be disregarded or dismissed as irrelevant, even undermining knowledge creep. Irrespective of the specific dimension of analysis, the more general point is that both the scope and the likelihood of knowledge creep and knowledge shifts can be linked to characteristics at the level of secondary institutional organization in the respective policy system or sector, specifically the way in which organizational epistemologies are rendered contestable or insulated from the intrusion of conflicting knowledge.

\section{Summary and conclusions}

This article has inquired into the political use of knowledge in the policy process. Throughout the analysis, an effort was made to identify insights from dispersed fields of research that can contribute to a more complete conceptualization of the use of knowledge in the policy process and advance the aim of integrating knowledge research and studies of the policy process more closely. In its focus on the conceptual use of knowledge, the article reflects the overall theoretical reorientation in this field of study over the past decades. This does not mean that instrumental knowledge use has failed to attract academic attention. As argued above, much of the recent debate on evidence-based policy making can be read as an extension of this research tradition. At the same time, the existing literature on conceptual knowledge use was nevertheless seen as highly incomplete. A first serious problem with the existing literature is that it routinely conflates conceptual and substantive use. The near exclusive research emphasis is on the question of how knowledge use can inform the formulation of policy alternatives. The article has argued that conceptual knowledge use has both a substantive dimension and a political dimension. Existing conceptualizations of the political use of knowledge, however, have remained so uniformly minimalistic as to prevent any meaningful investigation of the phenomenon. The article therefore introduced a broader definition of political knowledge use that emphasized the role of knowledge in contests over policy authority and the structure of political control. A second problem with the existing literature on conceptual use was that it remains largely silent on the range of underlying mechanisms. The concept of knowledge creep, as Weiss argued herself, has 
remained little more than a descriptive metaphor. In this context, the role of organizational epistemologies was discussed to underscore that the use of conceptual knowledge in the policy process is bound by organizationally embedded rules of observation and inference in ways much of this literature has failed to address. As a result, the implicit notion of policy learning as the main driver of conceptual knowledge use in the enlightenment model was partially rejected in favor of a logic of administrative and political contestation. This allowed the analysis to differentiate between knowledge creep and knowledge shifts as two distinct types of knowledge effects in the policy process. While knowledge creep is associated with incremental policy change within existing policy structures, knowledge shifts were linked to more fundamental policy change in situations when policy institutions themselves undergo some level of transformation. The remainder of the article tentatively identified conditions under which knowledge creep or knowledge shifts are expected to become more likely by showing how the structure of policy systems or sectors at the level of secondary institutional organization can render knowledge in the policy process more or less contestable.

Along the way, the analysis has taken issue with some widely accepted positions in knowledge research. In particular, the common contention that conflict invariably constrains the use and counteracts the effects of knowledge in the policy process was fundamentally called into question. In Weiss' (1999: 471) analysis, the 'endemic priority of politics' in organizational decision making is seen as the main reason why knowledge does not play a larger role in policy formulation. The article has contended that this conclusion is largely the result of the conceptual limitations of important parts of this literature. In a similar vein, the frequent association of the political use of knowledge with 'endarkenment' (Weiss 1979) as opposed to 'enlightenment' appears largely unfounded. The baseline assumption of the preceding analysis was that conflicting knowledge can be used to contest given structures of policy authority. This logic implies that political knowledge use is reflective of the way policy-making structures process information selectively. The article has also made it clear, however, that any theory of knowledge use that takes the effects of organizational epistemologies seriously views the role of knowledge in the policy process as bound by structural constraints in even the best of circumstances. To understand the mechanisms through which these boundaries can become contested and occasionally readjust to reflect evolving problem perceptions in the policy process is therefore crucial—not only for a better understanding of the disruptive effects of knowledge shifts, but also for assessing the ways in which knowledge can illuminate complex policy choices.

Open Access This article is distributed under the terms of the Creative Commons Attribution 4.0 International License (http://creativecommons.org/licenses/by/4.0/), which permits unrestricted use, distribution, and reproduction in any medium, provided you give appropriate credit to the original author(s) and the source, provide a link to the Creative Commons license, and indicate if changes were made.

\section{References}

Baumgartner, F. R. (2013). Ideas and policy change. Governance, 26(2), 239-258.

Baumgartner, F. R., \& Jones, B. D. (1993). Agendas and instability in American politics. Chicago: University of Chicago Press.

Baumgartner, F. R., \& Jones, B. D. (Eds.). (2002). Policy dynamics. Chicago: University of Chicago Press.

Bennett, C. J., \& Howlett, M. (1992). The lessons of learning: Reconciling theories of policy learning and policy change. Policy Sciences, 25(3), 275-294. 
Caplan, N. (1979). The two-communities theory and knowledge utilization. American Behavioral Scientist, 22(3), 459-470.

Dery, D. (1983). Decision making, problem-solving and organizational learning. Omega, 11(4), 321-328.

Dery, D. (1986). Knowledge and organizations. Policy Studies Review, 6(1), 14-25.

Dery, D. (1990). Data and policy change: The fragility of data in the policy.

Feldman, M. S. (1989). Order without design: Information production and policy making. Stanford: Stanford University Press.

Fischer, F. (2003). Reframing public policy. Discursive politics and deliberative practices. Oxford: Oxford University Press.

Fischer, F., \& Forester, J. (Eds.). (1993). The argumentative turn in policy analysis and planning. Durham: Duke University Press.

Hall, P. A. (1993). Policy paradigms, social learning, and the state: The case of economic policymaking in Britain. Comparative Politics, 25(3), 275-295.

Head, B. W. (2013). Evidence-based policymaking-Speaking truth to power? Australian Journal of Public Administration, 72(4), 397-403.

Head, B. W., \& Alford, J. (2015). Wicked problems: Implications for public policy and management. Administration and Society, 47(6), 711-739.

Holzner, B., \& Fisher, E. (1979). Knowledge in use. Considerations in the sociology of knowledge application. Knowledge: Creation, Diffusion and Utilization, 1(2), 219-244.

Howlett, M., \& Migone, A. (2011). Charles Lindblom is alive and well and living in punctuated equilibrium land. Policy and Society, 30(1), 53-62.

Huber, G. P. (1991). Organizational learning: The contributing processes and the literatures. Organization Science, 2(1), 88-115.

Huberman, M. (1987). Steps toward an integrated model of research utilization. Knowledge: Creation, Diffusion and Utilization, 8(4), 586-611.

James, T. E., \& Jorgensen, D. (2009). Policy knowledge, policy formulation, and change: Revisiting a foundational question. Policy Studies Journal, 37(1), 141-162.

Jones, B. D. (1994). Reconceiving decision-making in democratic politics. Attention, choice, and public policy. Chicago: University of Chicago Press.

Jones, B. D. (2001). Politics and the architecture of choice. Bounded rationality and governance. Chicago: University of Chicago Press.

Jones, B. D., \& Baumgartner, F. R. (2005). The politics of attention: How government prioritizes problems. Chicago: University of Chicago Press.

Jones, B. D, I. I. I., Thomas, H. F., \& Wolfe, M. (2014). Policy bubbles. Policy Studies Journal, 42(1), $146-171$.

Kay, A. (2011). Evidence-based policy-making: The elusive search for rational public administration. Australian Journal of Public Administration, 70(3), 236-245.

Knorr, K. D. (1977). Policymakers' use of social science knowledge-Symbolic or instrumental. In C. H. Weiss (Ed.), Using social research in public policy making (pp. 165-182). Lexington: Lexington Books.

Knott, J. H., \& Wildavsky, A. (1980). If dissemination is the solution, what is the problem? Knowledge: Creation Diffusion, Utilization, 1(4), 537-578.

Lindblom, C. E. (1968). The policy-making process. Englewood Cliffs: Prentice-Hall.

Mark, M. M., \& Henry, G. T. (2004). The mechanisms and outcomes of evaluation influence. Evaluation, $10(1), 35-57$.

Mead, L. M. (2015). Only connect: Why government often ignores research. Policy Sciences, 48(2), 257-272.

Newman, J., \& Head, B. (2015). Beyond the two communities: A reply to Mead's 'why government often ignores research'. Policy Sciences, 48(3), 383-393.

Oh, C. H. (1997a). Issues for the new thinking of knowledge utilization: Introductory remarks. Knowledge and Policy, 10(3), 3-10.

Oh, C. H. (1997b). Explaining the impact of policy information on policy-making. Knowledge and Policy, $10(3), 25-55$.

Pelz, D. P. (1978). Some expanded perspectives on use of social science in public policy. In J. M. Yinger \& S. J. Cutler (Eds.), Major social issues: A multidisciplinary view (pp. 346-357). New York: Free Press.

Pierson, P. (1993). When effect becomes cause: Policy feedback and political change. World Politics, 45(4), 595-628.

Radaelli, C. M. (1995). The role of knowledge in the policy process. Journal of European Public Policy, 2(2), 159-183. 
Rein, M., \& Schön, D. A. (1996). Frame-critical policy analysis and frame-reflective policy practice. Knowledge and Policy, 9(1), 85-104.

Rein, M., \& White, S. H. (1977). Policy research: Belief and doubt. Policy Analysis, 3(2), 239-269.

Rich, R. F. (1977). Use of social information by federal bureaucrats: Knowledge for action versus knowledge for understanding. In C. H. Weiss (Ed.), Using social research in public policy making (pp. 199-211). Lexington: Lexington Books.

Rich, R. F. (1991). Knowledge creation, diffusion, and utilization. Knowledge: Creation, Diffusion and Utilization, 12(3), 319-337.

Rich, R. F., \& Oh, C. H. (1993). The utilization of policy research. In S. S. Nagel (Ed.), Encyclopedia of policy studies (pp. 69-92). New York: Marcel Dekker.

Rich, R. F., \& Oh, C. H. (2000). Rationality and use of information in policy decisions: A search for alternatives. Science Communication, 22(2), 173-211.

Rittel, H. W. J., \& Webber, M. M. (1973). Dilemmas in a general theory of planning. Policy Sciences, 4(2), $155-169$.

Sabatier, P. A. (1986). Top-down and bottom-up approaches to implementation research: A critical analysis and suggested synthesis. Journal of Public Policy, 6(1), 21-48.

Sabatier, P. A. (1987). Knowledge, policy-oriented learning, and policy change. An advocacy coalition framework. Knowledge: Creation, Diffusion and Utilization, 8(4), 649-692.

Sabatier, P. A. (1988). An advocacy coalition framework of policy change and the role of policy-oriented learning therein. Policy Studies, 21(2/3), 129-168.

Sabatier, P. A. (1997). The status and development of policy theory: A reply to Hill. Policy Currents, 7(4), $1-10$.

Sabatier, P. A., \& Jenkins-Smith, H. C. (1988). Symposium editors' introduction. Policy Studies, 21(2/3), $123-127$.

Schön, D. A., \& Rein, M. (1994). Frame reflection: Toward the resolution of intractable policy controversies. New York: Basic Books.

Simon, H. A. (1962). The architecture of complexity. Proceedings of the American Philosophical Society, 106(6), 467-482.

Simon, H. A. (1973a). Applying information technology to organization design. Public Administration Review, 33(3), 268-278.

Simon, H. A. (1973b). The structure of ill-structured problems. Artificial Intelligence, 4, 181-201.

Webber, D. J. (1992). The distribution and use of policy knowledge in the policy process. In W. N. Dunn \& R. M. Kelly (Eds.), Advances in policy studies since 1950 (pp. 383-418). New Brunswick: Transaction Publishers.

Weber, E. P., \& Khademian, A. M. (2008). Wicked problems, knowledge challenges, and collaborative capacity builders in network settings. Public Administration Review, 68(2), 334-349.

Weible, C. M. (2008). Expert based information and policy subsystems: A review and synthesis. Policy Studies Journal, 36(4), 615-635.

Weiss, C. H. (1976). Using research in the policy process: Potential and constraints. Policy Studies Journal, $4(3), 224-228$.

Weiss, C. H. (Ed.). (1977a). Using social research in public policy making. Lexington: Lexington Books.

Weiss, C. H. (1977b). Research for policy's sake: The enlightenment function of social research. Policy Analysis, 3(4), 553-565.

Weiss, C. H. (1979). The many meanings of research utilization. Public Administration Review, 39(5), 426-431.

Weiss, C. H. (1980). Knowledge creep and decision accretion. Knowledge : Creation, Diffusion and Utilization, 1(3), 381-404.

Weiss, C. H. (1982). Policy research in the context of diffuse decision making. Journal of Higher Education, 53(6), 619-639.

Weiss, C. H. (1986). The circuitry of enlightenment: Diffusion of social science research to policymakers. Knowledge: Creation, Diffusion and Utilization, 8(2), 274-281.

Weiss, C. H. (1993). Where politics and evaluation research meet. Evaluation Practice, 14(1), 93-106.

Weiss, C. H. (1995). The haphazard connection: social science and public policy. International Journal of Educational Research, 23(2), 137-150.

Weiss, C. H. (1999). The interface between evaluation and public policy. Evaluation, 5(4), 468-486.

Weiss, J. A., \& Gruber, J. E. (1984). Using knowledge for control in fragmented policy arenas. Journal of Policy Analysis and Management, 3(2), 225-247.

Weiss, C. H., Murphy-Graham, E., \& Birkeland, S. (2005). An alternate route to policy influence: How evaluations affect D.A.R.E. American Journal of Evaluation, 26(1), 12-30. 
Weiss, C. H., Murphy-Graham, E., Petrosino, A., \& Gandhi, A. G. (2008). The fairy godmother-And her warts. Making the dream of evidence-based policy come true. American Journal of Evaluation, 29(1), $29-47$.

Whiteman, D. (1985). Reaffirming the importance of strategic use: A two-dimensional perspective on policy analysis in congress. Knowledge: Creation, Diffusion and Utilization, 6(3), 203-224.

Wildavsky, A. (1983). Information as an organizational problem. Journal of Management Studies, 20(1), 29-40.

Workman, S., Jones, B. D., \& Jochim, A. E. (2009). Information processing and policy dynamics. Policy Studies Journal, 37(1), 75-92. 